\title{
Scolding in Basic Schools: What the Counsellor Must Know?
}

\author{
Laryea, Prince ${ }^{1 *}$ Upoalkpajor, Joshua-Luther Ndoye ${ }^{2}$ Okae-Anti, Rose ${ }^{3}$ \\ 1.Institute for Distance and e-Learning (IDeL), University of Education, Winneba -Ghana \\ 2.Department of Psychology and Education, University of Education, Winneba -Ghana \\ 3.Institute for Distance and e-Learning (IDeL), University of Education, Winneba -Ghana
}

\begin{abstract}
The study aimed at exploring the experiences and perceptions of students and teachers on the use of scolding as a disciplinary measure and its counselling implications. The study was guided by the Kemmis and McTaggart model that proposed a spiral model of scolding comprising four steps: planning, acting, observing and reflecting. The study was qualitative in nature using the case study approach. Thirty six (36) respondents comprising twelve (12) teachers and twenty-four (24) students from two (2) Public Junior High Schools who were purposively selected. Data was gathered through interviews which was analysed thematically. The study findings revealed that, teachers used judgemental to subjective behaviours as well as evaluating the disciplinary measures to interpreting it as the appropriate measure to stop misbehaviour. Teachers start using verbal appreciation and stopped their habit of de-motivating students. Additionally, students experienced that teachers preferred to encourage students, who were not showing interest in classroom activities. It is recommended that teachers employ cooperative disciplinary measures as compared to punitive and harsh disciplinary measures to inspire children. On the flip side, counsellors should explore, develop, and implement classroom guidance and small group activities, as well as individual and group counselling interventions that can help students to better understand and adjust to classroom rules and expectations for behaviour.
\end{abstract}

Keywords: Scolding, Discipline, Student Behaviour, Kemmis and McTaggart model, Counselling Implication DOI: $10.7176 / \mathrm{JEP} / 10-32-10$

Publication date: November $30^{\text {th }} 2019$

\section{Introduction}

The assertion that discipline is the mother of all great achievements cannot be over emphasized in the field of education. Good discipline allows children to do their best in academic attainments and also leads to the effective achievement of the goals of the school and the aspirations of the community (Amoah, Laryea $\&$ Baiden, 2014). Schools are put up primarily to train students to become responsible adults so that they can conduct their affairs with dignity (Swift, 1999).

Amoah, et al., (2014) study indicated that although officially in Ghana many schools have extremely rigid code of behaviour, in practice, it appears many teachers find the students unmanageable and do not enforce discipline at all. Their studies further indicated that on the flip side there may be others who may impose brutal standards of discipline backed up with beating and whippings. In schools, where class size is typically 40 to 50 students, it appears maintaining order in the classroom can divert the teacher from instruction, leaving little opportunity for concentration and focus on what is being taught (Mensah, 2009).

Teachers are keenly concerned with maintaining pleasant, well-mannered behaviour in their classrooms. Therefore, there are times when they must use some form of discipline in order for class time to remain interesting and productive. However, some of the measures teachers adopt to manage misbehaviour are inappropriate and can seriously lead to violations of the rights of children (Amoah, et al., 2014).

Teachers in Ghanaian basic schools, which the public schools in the Effutu Municipality are not exception, sometimes fail to take into consideration factors which may not have been necessarily caused by the child yet go ahead to meet out measures which in their view are disciplinary. For instance, a child's failure to do his or her homework may indeed be due to factors at home outside his or her control. But it is the experience of many students that they are punished without account being taken either of their intentions or extenuating circumstances. Some children are not given the opportunity to explain themselves (Chaitey, 2012).

Thus, educational discipline enforced as a result of the violation of regulations occasionally lacks procedural protection of rights, where the rights and development of the child are not sufficiently considered, and opportunities for warnings and hearings are inadequate. Disciplinary measures adopted by teachers pertaining to student discipline in Junior High Schools (JHS) in the Effutu Municipality may be common and familiar to most people in other parts of Ghana (Amoah, et al., 2014). However, from the researcher's personal observation and interaction, reality and the day-to-day practice in most of the public JHS in the Effutu Municipality often come into conflict with this point of view.

Every now and then, the modern teacher faces a range of challenges in the school, trying to maintain a disciplined teaching environment. The Ghana Education Service and the Ministry of Education in conjunction with other stake holders such as the Ghana National Association of Teachers have developed rules which are 
supposed to regulate the discipline of school students in Ghana, however, scolding (speaking with students angrily to show disapproval of behaviour) as another disciplinary measure has not seen the light of day. Most teachers resort to the use of physical measures such as corporal punishment, other than the dialogue measure such as scolding in ensuring discipline in the schools. The study aimed at exploring the experiences and perceptions of students and teachers on the use of scolding as a disciplinary measure in classroom management and its counselling implications.

Based on the arguments raised, the question formulated to guide the study is: What are the experiences and perceptions of Junior High School students and teachers on scolding as a disciplinary measure in the Effutu Municipality?

\section{Conceptual Framework}

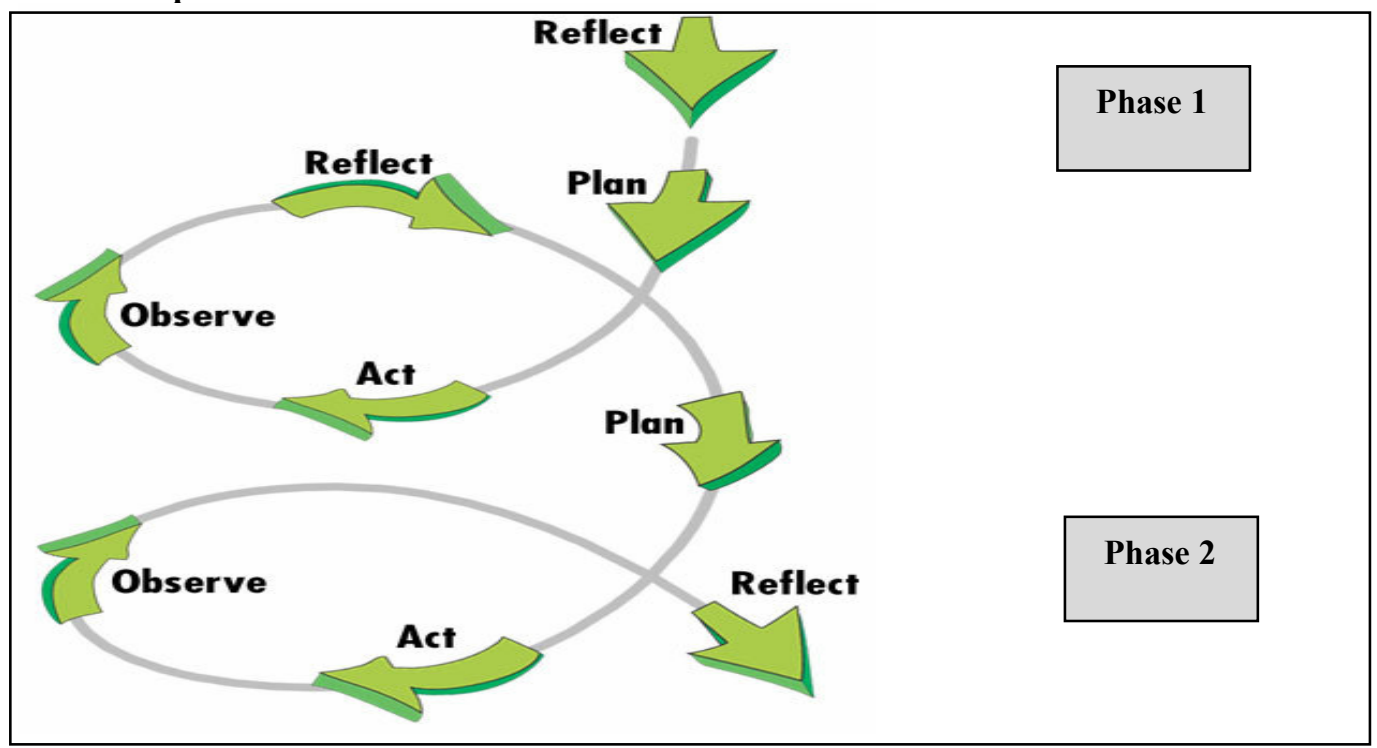

Figure 1: Kemmis and McTaggart (1988) Spiral Model of Scolding

The modern concept of discipline advocates that all those who have the responsibility should find creative ways of disciplining children in order to help them develop healthy lifestyles that are a reflection of respect for human rights (Dadzie, 2008). The study adopted the Kemmis and McTaggart's spiral model of scolding. They proposed a model comprising four steps within which the concept of scolding is applied: planning, acting, observing and reflecting.

\section{Methodology and Materials}

The study used the case study approach. The choice of a case study was to ensure a form of qualitative study which involves relatively small-scale studies for in-depth investigations, with the aim of exploring the experiences of Junior High School students on scolding as a disciplinary measure in real life situations.

Two schools were purposively selected from nineteen public schools in the municipality. These schools have varied but similar characteristics in terms of their location, the infrastructural developments and the calibre of teachers and students. In each school, the researchers used purposive stratified sampling technique to select the students and teachers. In view of the nature of the study, teachers were considered purposefully since they were directly responsible for managing behaviours in their classrooms. On the part of the students, the focus was mainly on those who were recipients of the teacher's disciplinary measure in class.

The interview guide and observation check list central to the research question were the instruments employed in the study. The usage of semi-structured interviews offered a versatile way of collecting data and applicable to all ages. Additionally, the choice was based on Welmann and Krugar, (2001) assertion that semistructured interviews allow the interviewer(s) to use probes with a view to clearing up vague responses, or asking for elaboration in case of incomplete responses. With the observation check list, Babbie (2007) indicated that, by going directly to the social phenomena under study and observing it as completely as possible, researchers can develop a deeper and fuller understanding of it.

In ensuring the trustworthiness of the instrument, the researchers adopted the member checking. According to Creswell (2009) member checking implies that the researcher(s) takes back parts of the polished product such as the themes, the case analysis, and the cultural description to the interviewee for affirmation. And in this case, the researchers took the final report of specific themes back to participants to determine whether what transpired during the interview session was recorded accurately. Methodological triangulation was used in this study and 
was achieved through the use of semi-structured interview guides and structured observation for data collection. The combination of two methods affected the quality of the data collect for the study.

Data emerging from the field was analysed through thematic approach. Similar ideas were grouped together to form sub-themes. These ideas were then fitted to give one main idea and conclusions were drawn. In some instances direct relevant quotations were reported verbatim.

\section{Findings and Discussion}

The study developed on the premise of a main research question. Four (4) themes were generated based on the transcripts of the respondents. These themes judgmental, supportive, evaluative, interpretative were summarised in Table 1 .

Table 1: Scolding Behaviours identified by teachers and students

\begin{tabular}{|l|l|l|}
\hline \multicolumn{2}{|l|}{ Scolding behaviours } & Participants/ comments \\
\hline Judgmental to Supportive & Judgmental & Scolds instructively, seek for clarification, \\
\cline { 2 - 3 } & Supportive & Empathetic and offers options in scolding \\
\hline Evaluative \\
Interpretative & Evaluative & $\begin{array}{l}\text { Prefers consistency of scolding } \\
\text { Always concludes on initial attempts. } \\
\text { Scolding based on disciplinary measures in the school }\end{array}$ \\
\cline { 3 - 4 } & Interpretative & $\begin{array}{l}\text { Self-evaluation and similar observations of disciplinary measure } \\
\text { used } \\
\text { Prefers giving thought to ideas well before responding. }\end{array}$ \\
\hline
\end{tabular}

The expressions with regards to judgemental comments about students' misbehaviour were:

By your judgement how did you find your performance? This is a poor performance because I was not impressed at all.

However, it was gathered that even though the student got feedback, the teacher kept saying, You have to try and expressed your challenges you encounter in order to help you else when you keep them, it won't solve the problem but rather aggravate it.

These quotes reveal the reactions of the teacher per the unsatisfactory behaviour of the student during lesson delivery. Although the teacher mirrored on the observed behaviour, it was suggestive that some expectations were held for the student to at least voice out his/her stance to the unsatisfactory behaviour. The two narratives situate itself in a two-way affair, i.e. a shared communication between the student and the teacher in the classroom. Further alternative choice of disciplinary measure is central to the views expressed from the teacher and the student.

However, some teachers tend to hold the belief that, since students' future was a matter of concern, they felt the students must be involved in the teacher's choice of disciplinary measures. This was further expressed:

The students also express the manner in which a teacher's choice of scolding used could seem a bit worrisome in the classroom. This at times makes teachers to think through on what may be if not good but appropriate measure to use in the wake of a student's misbehaviour rather than focusing on the orthodox ways of disciplining a student. I think personally that engaging students who misbehave to unravel the motive behind their behaviour could aid in effective disciplinary class management ...(a teacher expressed)

Furthermore, a teacher added

I sometimes unconsciously shout at students who misbehave during my lessons because those misbehaviours are annoying and sometimes can be irritating. And then unconsciously yell at them. However, irrespective of such unconscious tendency happening, I have resorted to dialoguing with my students which had proven to be helpful.

Conclusively, the choice of either judgmental or supportive scolding were based on the assertions held by teacher relative to experiences and emotional sentiments. That is to say whatever misbehaviour a student puts up and the corresponding choice of disciplinary measures is based on the teacher's informed thought. The teacher's engagement and dialoguing with students in striving to house the different forms of misbehaviours in the classroom were classified as the supportive scolding practices.

The study, however, revealed that in evaluative scolding as a means to discipline students, teachers explored alternatives from their own perspectives, that of colleagues and the laid down code of discipline in the school. It was ascertained that obviously teachers could face the difficulty with their explorations but could also look in-depth viewpoints to address discipline. A teacher remarked:

Exploring alternatives with evidence based approach are mostly employed by teachers. I can say that in my quest to judiciously use appropriate measures in the classroom, I reflect inwardly and sometimes observe what my colleagues do and carry out the most suitable for that moment.

The study gathered that in the ensuring classroom discipline, teachers resort to both summative and formative 
approaches. However, others were more concerned on the positivity of the disciplinary measures on student's behaviour on the classroom. The teachers held the view that being consistent with the kind of disciplinary measures in the classroom helps to build a clear understanding for the students.

I know that most teachers assess their choice of disciplinary measures in relation to what the school prescribes. Personally, I do not just discipline students, I evaluate my choice of measure based on the school's disciplinary code to ensure effective and efficient classroom management. I do this purposively to bring about a clearly understanding with sufficient evidence rather than just assessing the kind of approach that can or may work better (a female teacher).

Additionally, a teacher indicated:

Before considering the measure to adopt, teachers and my very good self, I think about the reformative approach more and that helps me to interpret the measure that is most effective rather than just evaluating what kind of approach is suitable. I believe that when you do a self-evaluation of the actions being exhibited by the student(s), one stands at a better position to interpret what approach is suitable to the observed misbehaviour.

The choice of teacher's disciplinary measures provide support for the schools' disciplinary measures, a teacher stressed,

In dealing with a student's misbehaviour, assessment of the measure to use is in conformity to what have been spelt out in the schools' code of discipline. Teachers need to recognise what misbehaviour has been exhibited in order to assess what measure to deploy in relation to what the school proposed.

Conclusively, the teachers engaged in making summative evaluations with respect to their own thinking of what could be appropriate. Aside being self-evaluative, their choices is sometimes reflective to other similar observations for better understanding. The choice of disciplinary measures were evaluated in the context of appropriateness rather than mere choice of carrying out.

In using scolding, harsh language or talking to students when they misbehave, the study findings revealed that teachers sometimes reflect on the misbehaviour through observation before they plan the necessary discipline to be meted out. In the event of reflecting, the teachers review their experiences and that of the laid down rules and regulations of the school before scolding the students. The study finding however was consistent with Kemmis and McTaggart (1988); Hatton and Smith (1995); McNamara, (1990) studies. Their studies put forward a set of self-motivating strategies for teachers: reflect immediately after a misbehaviour, on how it may happen and plan what to do differently next time; value your disciplinary measure; observe other teacher's disciplinary measures; and think through ways to overcome it; rearrange the classroom layout for maximal attention from students and call teacher study groups to resolve problems cooperatively. This is quite typical in the study observation in the study area.

\section{Implication for Counsellors}

Counselling in schools is a vital service in helping the stakeholders to understand themselves and their immediate environment in order to effectively function as members of that environment. This brings to fore, the role of school counsellor(s) or coordinator(s) in addressing and meeting the disciplinary issues in the schools. Thereby creating the needed awareness and atmosphere for effective classroom management practices. Scolding as a disciplinary measure or practice in schools, the school counsellor(s) ought to:

1. Develop knowledge and skills in coping with problem behaviours not only in the classroom, but in all areas of the school.

2. Consult with teachers who are trying to create more effective approaches to classroom discipline as well as with those who are struggling to respond to existing behaviour problems. A secondary benefit of these consultations is that the school counsellor systematically may examine the effectiveness of various discipline approaches and use this information as an additional resource for other teachers.

3. Explore, develop, and implement classroom guidance and small group activities, as well as individual and group counselling interventions that can help students to better understand and adjust to classroom rules and expectations for behaviour.

4. Research and document the effectiveness of disciplinary programs in the schools and evaluate the impact of these programs on students and their learning environment.

5. Encourage educators to involve students in making decisions about disciplinary approaches and policies. This increases student "ownership" of the resulting programs and fosters a greater sense of responsibility for behaviours and their consequences.

\section{Conclusion}

In every educational establishment, discipline is necessary for effective management, if the goals of the school 
are to be accomplished. In an effort to prevent and resolve students' discipline problems and ensure efficient functioning of schools and as such classrooms, there must be reasonable disciplinary policies and procedures. Disciplinary measures are therefore expected to be reasonable and properly meted out to offending students on account of the offence committed. Teachers' preference of scolding is to encourage students, who were not showing interest in classroom activities rather than inflicting pain on them. Reflecting on students' misbehaviour and ensuring the appropriate measure devoid of physical pain creates a harmonious teaching-learning environment.

It is therefore recommended that cooperative disciplinary measures as compared to punitive and harsh disciplinary measures should be enforced by educators to inspire children to make smart choices and develop positive behaviour.

\section{References}

Amoah, S. A., Laryea, P., \& Baiden, M. N. (2014). Teachers' and students' state in developing disciplinary strategies in schools: The case of two public Junior High School in Ghana. African Journal of Interdisciplinary Studies, 7, 34-44.

Babbie, E. (2007). The practice of social research. Belmont: Wadsworth Cengage learning.

Bryman, A. (2008). Social research methods. ( $3^{\text {rd }}$ ed.) New York: Oxford University Press.

Chaitey, S. A. (2012). Teachers' disciplinary approaches and the violation of pupils' rights in Ghana. Winneba: An Unpublished MPhil Thesis, University of Education, Winneba

Creswell, J. W. (2009). Research design: Qualitative, quantitative and mixed methods approaches. $3^{\text {rd }}$ ed. California: Sage Publications.

Dadzie, O. C (2008). Student discipline strategies: Research and practice. Albany, NY: State University of New York Press.

Hatton, N., \& Smith, D. (1995) Reflection in teacher education: Towards definition and implementation. Teaching and Teacher Education, Vol. 11, No. 1, pp. 33-49,

Kemmis, J. \& McTaggart, K. (1988) Beyond discipline. From compliance to community. U.S.A: ASCD Publications.

McNamara, D. (1990). Research on teachers' thinking: Its contribution to educating student teachers to think critically. Journal of Education for Teaching, 16(2), 147-160.

Mensah, G. A (2009) Examination of students' views on improving discipline in teacher training colleges: Implications to guidance and counselling. Cape Coast: An Unpublished MPhil Thesis, University of Cape Coast.

Swift, M. (1999). Discipline for life: Getting it right with children. Texas: Child right.

Welmann, C. J, \& Krugar, S. J. (2001). Research methodology in business and administrative sciences. Halfway House: International Thompson. 